\title{
Editorial
}

\section{Effect of Rheumatoid Arthritis upon Other Members of the Family}

Rheumatoid arthritis (RA) is usually defined as a chronic disease of the musculoskeletal system, provoking pain and disability. Often the disease progresses restricting functionality and lead to greater dependence.

An appropriate basic therapy, pain relief, orthopaedic surgery (including joint replacement) and emotional support help the patient to live better with RA. Life, however, remains a confrontation with limitations and loss of function. This demands an important adaptation on the part of the patient. Also those who live with him/ her are confronted with a problem : many activities of daily life can no longer be done in the same way as before. Both patient and family have to search for possibilities to make and keep life meaningful. In acute illness the family usually adapts itself spontaneously to the new situation (taking over certain tasks, and limiting social activities). In chronic illness this spontaneous reaction becomes a permanent duty. This by itself can create communication and relation problems.

The functioning of the RA patient and his environment is strongly determined by the way they learn to cope with stress factors and loss. In respect to dealing with illness and being ill something can be done. Everyone involved can contribute individually: the patient himself, the family, the health professional (hospital team, family doctor, self-help group).

\section{RA and uncertainty}

Very often some time has elapsed between the time the illness is diagnosed and the initial complaints of the patient suffering from RA.

After a period of minimalizing (opposition and "it will not be so bad") comes a period of anxiety and doubt. At this moment patients are often admitted to a hospital for further observation and diagnostic tests. There they are confronted with other possible stages of rheumatoid arthritis. For many of them this first confrontation provokes a serious emotional crisis.

Once the diagnosis has been made with certainty, the uncertainty expresses itself in another dimension: uncertainty concerning the further evolution (progression), uncertainty as to how one's partner will react, uncertain- ty concerning the periods of exacerbation, uncertainty concerning the effectiveness of medication, questions about heredity, ... in short, uncertainty about "how the next day will be".

Rheumatic patients often say that they cannot make plans and that they have to live from day to day. Only much later, when the disease is well established, are they able to accept it and develop a more positive attitude, namely, that most plans are often made and not executed.

For one's partner as well, and eventually for other family members, this uncertainty becomes a real problem. While an open communication can prevent problems, latent questions often remain. Questions such as "How can I after a full day of work listen to a pain story?", "How can I express my love physically?", "How will my child be cared for during the day?" All these questions are just a few examples involving daily life.

\section{RA and lack of understanding and non-recognition}

Fatigue and pain are the first complaints. These are symptoms which are not much appreciated in the medical world because they are difficult to objectivize, to measure. Even when we look around us, we realize that these words, fatigue and pain, have different meanings for most people. They are subjective expressions. Therefore it is understandable that patients encounter lack of comprehension. Initially, the patient himself/herself neglects and refutes these observations of pain and fatigue. $\mathrm{He}$ does not understand himself. He has never been squeamish about pain. He asks himself what is happening with him and looks for explanations. Then the relatives start to question the magnitude of the complaints. For instance, small children cannot understand why mamma does not lift them up. Older children do not understand why the meal is not ready when they return home from school. The partner feels uneasy when his wife does not feel like having sex. In this situation of "incomprehension", the patient starts to build up feelings of guilt and feels useless.

The general practitioner and the specialist realize insufficiently the complaints of the patient. They minimal- 
ize them and do not start a profound diagnostic exploration. Employed patients often experience misunderstanding from colleagues (who have had to take over some tasks), from the employer (because of frequent sick leaves) or from the controlling doctor of the insurance company.

Dependent on the relation between the patient and his/her partner, the latter will feel himself a victim or supported by other people.

When the disease is in a chronic phase, patients often feel they are no longer permitted to talk about their disease. The immediate environment keeps silent over the handicap and disability and also the greater environment (the city or village) is not very handicap-minded. Healthy people do not think spontaneously about what it means for a disabled person to be confronted with inaccessability to public buildings, inability to open a bottle or a vacuum package.

An open dialogue, real communication between the sick person and the people with whom he has to live together is extremely important. When a patient can rely on his partner and vice versa, when the partner can express his/her problems, then there is a real possibility of a solution which will suit both.

\section{RA and loss}

The experience of loss is probably the most important factor in learning how to live with RA. The losses are mainly a consequence of limitation of mobility, chronic pain and deformities.

\section{Loss of independence}

Knowledge of the need to be dependent on medication, on technical helps and gadgets, on family support, is in general difficult for the patient to accept. No doubt, when the patient becomes dependent upon others for a number of essential primary needs, he experiences this as an attack on his personality (for help in eating, for cleaning up after use of the toilet). An investigation in our rheumatology unit in Pellenberg revealed that one third of the tensions between partners originate due to this dependence (always asking for help).

\section{Loss of work and income}

Employed men and women were often obliged to change their work situation because of the disease. In the majority of the cases change in work situation means a complete stop of work. Loss or change of work, means a change in income. Often the only resource is a minimum compensation, and thus, the final income will be lower than they were accustomed to.

\section{Loss of financial possibilities}

With a decrease in income and an increase in expenses (therapy, extra aid, etc.) the amount of money available is substantially reduced.

\section{Loss of social contacts and activities}

Patients are of necessity forced to stay at home. The family limits their social activities to a minimum. Friends and relatives visit less frequently. Danger of isolation becomes very real. An evening out, film, theatre or concert visits, shopping... all are activities which gradually disappear.

\section{Loss of image}

Deformities of feet and hands, side-effects of medication (e.g. loss of hair, swollen face, ...) often result in serious changes in appearance. Frustrations and shame with respect to one's partner, towards one's children and neighbours are frequent. When the patients gets a flare up she loses the desire to dress up or make up. In fact, the partner has some difficulty in accepting this change and sometimes resorts to reproach. The body image accentuated by society does not correspond to the frustration of the patient and the partner.

\section{Loss of sexuality}

Pain, fatigue, loss of mobility create a situation in which the patient cannot respond appropriately to the expectation of the partner. Much more serious are the mutual emotional aspects ; the wife may think that her hands are no longer able to caress; the husband may feel that his handicapped wife is no longer sexually attractive. Education towards a healthy sexuality, which gives satisfaction to both the patient and the partner, is an important aspect of assistance. A spontaneous but respectful approach to this delicate matter by the health professional may be the beginning of a satisfactory change in life.

\section{Loss of the normal role pattern}

The family has built up a reliable role pattern. This pattern, however, is broken in the case of serious illness such as a chronic illness. The wife can no longer do the normal housework and many tasks have to be taken over by others. A man who loses his job is not able to provide his family with the same level of income. The partner who now becomes the breadwinner, may feel superior. In another case, the healthy partner may now be obliged to seek work. A change in role pattern usually gives rise to guilt feelings in the patient. On the other hand, the partner feels obliged to take over a number of tasks. These unexpressed feelings are often a major cause of conflict and stress. We should also note that some patients are able to continue their role; we call this "role intactness". 


\section{Loss of self-esteem}

A positive judgment about oneself is an important component in keeping oneself in good physical and mental health. The patient can himself undertake certain measures in order to grow in a positive self-esteem (through self-analysis, by deliberately finding positive elements). Other people as well may help to influence the self-image.

\section{Living with loss}

People confronted with disease or illness develop a certain reaction pattern. This pattern is called "coping behaviour". In the recent literature we find that "coping behaviour" is more important for the patient's health than the disease itself. Each human being experiences this loss in his own way, but in this coping process some generalities can be distinguished. Dr. Diekstra, a Dutch health psychologist, puts forward the observation that an individual who experiences a serious event is faced with four tasks (1). (I would like to stress that the term individual refers to the patient as well as his partner).

First, the emotional disorganization must be kept within acceptable limits. A condition for this is that the person involved is ready to accept the reality of loss and the emotional pain it involves. At first sight, negation would seem to be a soluion, but after some time, the person will be faced with reality. Secondly, self-esteem should be maintained. A positive judgment about oneself can be influenced favourably by the patient himself, by others or by the event itself. Thirdly, the patient maintain one's own network of interpersonal relationships. Positive relation patterns can help the patient and his family to reduce grief. Fourthly, all those involved should endeavour to adapt themselves to the new life situation. The search for satisfactory alternatives helps to counteract disappointments. Step by step one learns to see what can be done instead of staring blindly at what cannot be done. This is a dynamic process. Attempts at overcoming difficulties sometimes end in failure, so that the coping process must start all over again.

In conclusion, we can say that the start of a "loss experience" means an acute crisis. This crisis can hurt the family members more than the patient him- or herself (tolerance, reality conception). The patient reacts often in a regressive way (limited attention, egocentrism). The crisis is usually followed by disorganisation; each one has his/her own way of assimilation. Often these reactions deviate. Especially difficult are the situations when the partner does not understand the disease and reacts with overprotection, or when the patient reacts with extreme dependence. Gradually, the patient and his envi- ronment come to a reorganization in which situations are reassessed and in which further options are crystallized.

\section{Important aspects of counseling other family members}

We already mentioned that an open dialogue between patient and family is a must. The patient and his immediate environment have to understand each others behaviour. Usually this behaviour has to be explained mutually. We may not lose sight of other systems : the parents of the patient, married children, grandchildren, workmates...

Families in a "process of formation" need special attention. Because members of this system are emotionally more vulnerable, they will be less capable of putting up with difficulties. In general, also transitions to other family phases are difficult periods in which the family lacks the necessary courage. Indeed, a great deal of emotional strength is required to go through these transitions. It is important to know how the environment considers the sick-role (a sick person, an imaginary invalid, an exploiter).

Finally, it is important for us as health professionals, working from an admission-setting, to prepare with great care the transition to the home situation. At home, problems will really be felt more intensely and a lot of devotion will be required from the environment.

Our attention for the family has to be situated at two levels. First, there is the family as a client with its own problems (and its own losses). Second, there is the family as renderer of assistance. The family members can be brought to act positively, but we may not forget this is sometimes difficult because they too are going through a crisis. Family members will easily comfort and spare each other. The specific position of the family is important. Very often family members are considered as an extension of the health professionals : they nurse the patient, they control his diet and use of medication ...

\section{Tips for health professionals}

Finally, I would like to end by formulating some specific points of interest for health professionals.

1) The family consists of the nearest relations mentioned by the patient himself; 2) The family does not exist. Great differences can exist among family members. Each one reacts differently to a happening. It is clear that the nearest relations of different patients also react in a different way and this requires another approach ; 3) Involving the family in the process of care- 
taking starts with accepting their existence in relation to the patient. Questions like "How did your partner react ?" or "What support did you experience ?" can be of help ; 4) Approaching the patient together with his family can stimulate the mutual experience; 5) Children have to be involved in the grief. Giving them the appropriate information will give them something to hold on to. It is in speaking about feelings that children learn the deeper meaning of sentiment, love and emotion, thus creating in the family environment an openness to human situations.

W. Peeters

Chairman

EULAR Standing Committee for Health Professionals

REFERENCE

1. Diekstra, R.F., Gill, K. Verdriet, verliesverwerking en gezondheid. Ambo 1988, pp. 240.
Correspondence to W. Peeters, Department of Rheumatology, University Hospital KUL, 3212 Pellenberg, Belgium. 